\title{
The influence of non-starch polysaccharide on thermodynamic properties of starches from facultative wheat varieties
}

\author{
Justyna Rosicka-Kaczmarek ${ }^{1}$ Mariola Tkaczyk $^{2}$ - Bartłomiej Makowski ${ }^{1}$. \\ Aleksandra Komisarczyk ${ }^{1} \cdot$ Ewa Nebesny $^{1}$
}

Received: 3 February 2017 / Revised: 23 May 2017 / Accepted: 4 June 2017 / Published online: 20 June 2017

(c) The Author(s) 2017. This article is an open access publication

\begin{abstract}
The effect of sowing time of three facultative wheat varieties (late autumn or spring) on the content and properties of arabinoxylans (AX) adsorbed on the surface of starch granules in the process of washing out from flour, and the impact of AX on physicochemical properties of starch and filtration performance of enzymatic starch hydrolysates were determined in this study. The differential scanning calorimetry (DSC) was used to assess the susceptibility of native starches and starches deprived of AX to gelatinization and hydrolysis by $\alpha$-amylase (under conditions used in industry). Processes of amylose-lipid complexes (AML) dissociation and re-association were monitored to determine values of transition enthalpy $(\Delta H)$, temperatures of the onset $\left(T_{\mathrm{o}}\right)$, peak $\left(T_{\mathrm{p}}\right)$ and completion $\left(T_{\mathrm{c}}\right)$ of the transition as well as to calculate $\Delta T_{\mathrm{r}}\left(T_{\mathrm{c}}-T_{\mathrm{o}}\right)$. The time of wheat sowing affected properties of AX associated with starch granules that in turn influenced the characteristics of starch and its enzymatic hydrolysates. The presence of $\mathrm{AX}$ in starch granules negatively affected filtration of glucose syrups obtained under the same conditions as in industry.
\end{abstract}

Justyna Rosicka-Kaczmarek

justyna.rosicka-kaczmarek@p.lodz.pl

1 Faculty of Biotechnology and Food Sciences, Institute of Food Technology and Analysis, Lodz University of Technology, Stefanowskiego 4/10, 90-924 Lodz, Poland

2 Department of Physical Chemistry, University of Lodz, Pomorska 165, 90-236 Lodz, Poland
Keywords Facultative wheat · Starch granule · Arabinoxylans · Gelatinization · Enzymatic hydrolysis . Compressibility of filtration cake

\section{Introduction}

Substances inherently associated with starch granules, like lipids and proteins, either attached to the surface or located inside, affect swelling and gelatinization of starch [1-3]. Particularly potent effectors are lipids that either bind to the surface or are incorporated into amylose-lipid inclusion complexes (AML) [4-7]. The presence of lipid complexes in starch granules is observed as a hydrophobic nucleus situated within helices formed by amylose chains. The lipid complexes vary between $0.15-0.55 \%$ of the amylose fraction in cereal starches. Lipids in starch granules, despite representing a small fraction, can significantly reduce the swelling capacity of the starch paste [8]. Not less important are non-starch polysaccharides such as arabinoxylans (AX, pentosan) that are often encountered components of cereal starch granules $[9,10]$. The endosperm cell walls are disrupted during milling of the wheat grain, and during subsequent starch/gluten separation small particles of cell wall material are mixed with the starch fraction. The cell wall material is rich in the pentosan (at least 70\%) and constitutes a high proportion of the pentosan found in the starch fraction [10]. Starch is one of the principal sources of glucose for other conversions. Production of enzymatic starch hydrolysates, containing $93-98 \%$ glucose, is a twostep process, beginning with starch liquefaction to dextrins, catalyzed by $\alpha$-amylase, which is followed by saccharification to glucose, catalyzed by glucoamylase. Glucose syrups obtained this way are subjected to filtration and refining to remove the remaining solids and impurities, which 
negatively affect their quality [9-11]. The efficiency of enzymatic starch hydrolysis is strongly affected by the presence of non-starch components of granules, such as lipids, proteins and non-starch polysaccharides, mainly AX.

The influence of arabinoxylans on the quality of starch hydrolysates from various cereals has been intensively studied because AX absorb large amounts of water and form highly viscous gels that may negatively affect processes of enzymatic starch hydrolysis $[10,12]$ and filtration of hydrolysates obtained from cereal starches [13]. Because of the high water holding capacity, water-extractable arabinoxylans reduce rates of many technological processes (including those in the starch industry). WEAX can form complexes with soluble starch fraction or proteins present on the surface of starch granules. Such complexes negatively affect the dynamics of enzymatic hydrolysis because of the reduced access of amylolytic glycoside hydrolases to starch chains. Results of certain studies suggested that not only the total concentration of AX but also the WEAX/ WUAX ratio and branching pattern influence the rate of filtration of enzymatic starch hydrolysates and their quality, i.e. transparency and glucose concentration [9-11].

Apart from genetic factors, also climatic conditions during the growth of wheat and grain formation may decide the chemical composition of grains and starch granules. For instance, the content of lipids increases with the rise in temperature of wheat maturation [14-17]. A diminishing interest in the cultivation of spring cereals, in particular spring, wheat varieties, is a consequence of even twice lower crop yields compared to winter varieties. The reduced crop yields are caused by an increasing water deficit and low precipitation during spring and summer that negatively affect the growth of spring wheat varieties [18]. Therefore, they have been increasingly replaced by facultative ones.

Facultative (or alternative) varieties of cereals are spring varieties that can be sown either in spring or late autumn (or even early winter) [19]. Irrespective of sowing time they fully develop and produce ears containing grains. However, only a few varieties of cereals are tough enough. All of them bear a cold-acclimation gene that allows surviving winter season and makes these plants more resistant to adverse environmental conditions. Facultative cereal varieties can be sown even in January or February if climate conditions are mild enough. These cereals prefer areas with mild winters and high precipitation in autumn, like Middle Asia, Chile, Middle East, Australia, Belgium, France, Slovakia, south Germany and Balkan Peninsula [20]. Because of the global warming effect and low spring precipitation, facultative varieties of cereals have been increasingly popular. They may be sown late autumn, after harvests of sugar beets or other cereals because they need shorter vernalization periods than typical winter varieties [19]. Crop yields of facultative cereals depend on sufficient supply of water from winter precipitation. Maturation and harvesting of facultative and winter varieties occur almost simultaneously which enables using the same fields for the production of rape (this is usually impossible after harvesting of spring cereals) $[21,22]$. There are no reports on the effect of sowing time of facultative wheat varieties on the amount and characteristics of non-starch polysaccharides such as arabinoxylans associated with the surface of starch granules. Because also the AX, apart from lipids and proteins, may influence the course of technological starch processing and quality of starch hydrolysates, the authors of this work decided to determine the impact of wheat sowing time on the level of AX adsorbed on the surface of starch granules in the process of washing out from flour as well as their effect on starch gelatinization and thermodynamic properties of AML complexes (enthalpies and temperatures of their association and dissociation) occurring in both liquefied starch and its enzymatic digests. These parameters were determined by the differential scanning calorimetry (DSC). The effect of AX removal on filtration performance of glucose syrups produced from the tested starches, isolated from the facultative wheat varieties, was also determined.

\section{Materials and methods}

\section{Materials}

Starch-rich fractions were isolated from grains of 3 facultative wheat varieties: Nawra, Cytra and Koksa (registered in a national register of wheat varieties-COBORU; Cytra in 2004-quality group B, Nawra and Koksa in 2008-quality group A), which were grown as the spring and winter (sown late autumn) ones, and harvested in 2012. These varieties were cultivated under the same climatic and agronomic conditions by the Institute of Plant Breeding and Acclimatization in Strzelce (field in Kończewice, Poland). Six batches of grains obtained this way (2 batches for each variety) were milled and resulting flours were used to isolate starches. All these wheat varieties were classified as medium-hard, based on results of hardness measurements using a 4100 Single Kernel Characterization System (SKCS, Perten Instruments) [23]. This analysis consisted of measurements of the hardness of 300 grains of a cereal, conducted in triplicate, as described by the authors elsewhere [24]. The values of grain hardness were: 58 and 64, 55 and 57, and 65 and 66, for the spring and autumn 
(referred to as winter in [24]) crops of Koksa, Nawra, and Cytra, respectively.

Enzymatic hydrolysis of starch-rich fractions was conducted under the same conditions as in industry and catalyzed by the following enzymes:

- $\alpha$-amylase (EC 3.2.1.1, $\alpha$-1,4-glucan glucanohydrolase) Liquozyme Supra (135 KNU g ${ }^{-1}$, Novozymes, Bagsvaerd, Denmark), which was applied in a ratio of $0.0004 \mathrm{KNU} \mathrm{g}^{-1}$ d.w. starch $(0.0003 \%$ d.w. starch); 1 Kilo Novo Unit is the amount of enzyme which degrades $4870 \mathrm{mg}$ of starch dry matter in $1 \mathrm{~h}$ under standard conditions,

- glucoamylase (EC 3.2.1.3, $\alpha$-1,4-glucan glucohydrolase) Dextrozyme (255 AGU $\mathrm{g}^{-1}$, Novozymes, Bagsvaerd, Denmark), which was applied in a ratio of $0.0867 \mathrm{AGU} \mathrm{g}^{-1}$ d.w. starch hydrolysate $(0.34 \mathrm{~kg}$ enzyme/1000 kg d.w. hydrolysate).

All chemicals and reagents used in this study were of analytical grade (Sigma-Aldrich, Germany).

\section{Methods}

Each of six starch-rich fractions samples were washed using a method of Martin Process [25], which was modified by the authors [24] from dough prepared by mixing flour and water in a ratio of 2:1 (w/w) and incubated for $30 \mathrm{~min}$ to form gluten matrix. Starch-rich fractions was washed with the running cold tap water until the negative reaction of the remaining gluten with Lugol reagent (solution of $I_{2}$ in $\mathrm{KI}$ ), and recovered from resulting suspension by repeated sedimentation at $5{ }^{\circ} \mathrm{C}$ (to prevent oxidation and degradation of lipids and proteins).

\section{Chemical composition of starch granules}

The isolated starch-rich fractions were analyzed for: dry matter content [24], protein content by Kjeldahl method, according to the American Association of Cereal Chemists (AACC) procedure [26], total lipid content by Soxhlet-Weibull method, with acid hydrolysis [24], and nonstarch polysaccharides (arabinoxylans) content by gas chromatography. The latter method relied on AX hydrolysis to monosaccharides (xylose and arabinose) using $2 \mathrm{M}$ trifluoroacetic acid (TFA) at $110{ }^{\circ} \mathrm{C}$ and reduction of these pentoses to volatile derivatives (alditols) [27]. The analysis was performed using a Varian 450-GC gas chromatograph equipped with a VF-23 ms Factor Four Capillary column $(60 \mathrm{~m} \times 0.25 \mathrm{~mm} \times 0.25 \mu \mathrm{m})$. All results were expressed on a dry weight basis.
Extraction of non-starch polysaccharides from starch granules

To determine the effect of $\mathrm{AX}$ adsorbed to the surface of starch granules in the process of washing out from flour, on the susceptibility of starch to gelatinization and hydrolysis by $\alpha$-amylase, the $\mathrm{AX}$ were extracted with water and then with saturated $\mathrm{Ba}(\mathrm{OH})_{2}$. This enabled to remove separately the water extractable arabinoxylans (WEAX) and water unextractable arabinoxylans (WUAX). To extract WEAX, starch slurries (starch: water ratio of 1:2) were mixed for $2 \mathrm{~h}$ (room temperature) using a magnetic stirrer (the first step) and centrifuged for $15 \mathrm{~min}$ at $4600 \mathrm{rpm}$ (the second step). This procedure was repeated once more and the separated starch was dried at room temperature. Then the WUAX fraction was extracted from the starch by mixing its suspension in aqueous $\mathrm{Ba}(\mathrm{OH})_{2}$ solution (the saturated solution supplemented with $5 \% \mathrm{w} / \mathrm{v} \mathrm{NaBH} 4$ ) for $16 \mathrm{~h}$ (room temperature, starch: solution ratio of 1:2) using the magnetic stirrer, and centrifuging for $15 \mathrm{~min}$ at $4600 \mathrm{rpm}$ (also this two-step procedure was repeated once more). The separated starch was dried at room temperature and used for further analyses.

\section{The degree of substitution of xylose residues} with arabinose moieties

The structure of AX isolated from the starch-rich fractions of interest, it means the number of xylose residues that were substituted with arabinose units was determined by the magnetic resonance ${ }^{1}$ HNMR. Samples of AX (30 mg each) were dissolved in aliquots $(1 \mathrm{ml})$ of deuterium water $\mathrm{D}_{2} \mathrm{O}$ that contained the standard DSS. To achieve complete dissolution of AX, these samples were incubated overnight at room temperature using the shake platform. Then, they were centrifuged two times $(6300 \mathrm{~g}, 5 \mathrm{~min})$ and the supernatants were analyzed using a Bruker Avance III 500 $(11.7 \mathrm{~T})$ apparatus. The spectra were resolved at $85^{\circ} \mathrm{C}$ as described by [28].

\section{Thermodynamic properties of starch and dissociation/ re-association of AML complexes}

Thermal analysis was conducted by the DSC for the native starch-rich fractions and starches obtained by extraction of AX fractions from the surface of starch granules. This analysis enabled to determine the susceptibility of these starches to gelatinization and hydrolysis by $\alpha$-amylase. Also, the impact of AX on properties of AML complexes was estimated.

DSC analyses were carried out using a MICRO DSC III calorimeter from Setaram Instruments (France) [24]. Nitrogen (purity of $99.95 \%$ ) was used as the purge gas at a flow 
rate of approximately $20 \mathrm{~mL} \mathrm{~min}{ }^{-1}$. Indium (mp-156.6 ${ }^{\circ} \mathrm{C}$, $\Delta H_{\mathrm{f}}=28.45 \mathrm{~J} \mathrm{~g}^{-1}$ ) was used for the calibration of the DSC instrument.

\section{The effect of $A X$ on starch gelatinization}

Triplicate samples (about $200 \mathrm{mg}$ ) of native starch-rich fractions and AX-free starches were weighed to a steel, high-pressure, type "batch" cell, and thoroughly mixed with water at the starch/water ratio of 30:70 (w/w). The cell was then hermetically sealed and allowed to equilibrate at room temperature $\left(18-20 \pm 2{ }^{\circ} \mathrm{C}\right)$ before the analysis $(1 \mathrm{~h})$. An empty, hermetically sealed cell was used as a reference. The suspensions of starch were subjected to heating from $18{ }^{\circ} \mathrm{C}$ to $120^{\circ} \mathrm{C}$ at a scanning rate of $1{ }^{\circ} \mathrm{C} \mathrm{min}{ }^{-1}$ and cooling from 120 to $18{ }^{\circ} \mathrm{C}$ at the same scanning rate. Starch gelatinization and processes of AML complexes dissociation and re-association, occurring during the first and the first and second step, respectively, were monitored to determine values of transition enthalpy (expressed in $\mathrm{J} \mathrm{g}^{-1}$ d.w. starch) and temperatures of the onset $\left(T_{\mathrm{o}}\right)$, peak $\left(T_{\mathrm{p}}\right)$ and completion $\left(T_{\mathrm{c}}\right)$ of the transition [24].

\section{The effect of AX on starch hydrolysis by $\alpha$-amylase}

The suspension of starch-rich fractions in water (30:70 w/w) was mixed with $\alpha$-amylase $(0.0003 \%$ of starch dry weight $-0.0004 \mathrm{KNU} \mathrm{g}^{-1}$ d.w. starch, the same enzyme: starch ratio is used in industrial processes of starch liquefaction). The cell was then hermetically sealed and allowed to equilibrate at room temperature $\left(18-20{ }^{\circ} \mathrm{C} \pm 2{ }^{\circ} \mathrm{C}\right)$ before the analysis $(10 \mathrm{~min})$. An empty, hermetically sealed cell was used as a reference. In this case, the process consisted of the following steps: heating from 18 to $95{ }^{\circ} \mathrm{C}\left(1{ }^{\circ} \mathrm{C} \mathrm{min}^{-1}\right)$, isothermal incubation at $95{ }^{\circ} \mathrm{C}$ (40 min), cooling from 95 to $40{ }^{\circ} \mathrm{C}\left(1{ }^{\circ} \mathrm{C} \mathrm{min}^{-1}\right)$, heating from 40 to $120^{\circ} \mathrm{C}\left(1{ }^{\circ} \mathrm{C} \mathrm{min}{ }^{-1}\right)$, cooling from 120 to $18{ }^{\circ} \mathrm{C}\left(1{ }^{\circ} \mathrm{C} \min ^{-1}\right)$. The temperature of $95{ }^{\circ} \mathrm{C}$ and time of $40 \mathrm{~min}$ are the parameters of industrial starch liquefaction. As in the study described above, starch gelatinization and processes of AML complexes dissociation and re-association, occurring during the successive steps, were monitored to determine values of transition enthalpy (expressed in $\mathrm{J} \mathrm{g}^{-1}$ d.w. starch) and temperatures of the onset $\left(T_{\mathrm{o}}\right)$, peak $\left(T_{\mathrm{p}}\right)$ and completion $\left(T_{\mathrm{c}}\right)$ of the transition [29].

\section{Enzymatic starch conversion to glucose syrups}

Processes of enzymatic hydrolysis of native starch-rich fractions and starch-rich fractions obtained by extraction of AX from the surface of starch granules were performed in a laboratory scale [11]. Wheat starch slurries $\left(300 \mathrm{~cm}^{3}\right.$,
30/70 — starch/water, $\mathrm{pH}$ 5.2-5.4) were placed in a converter and liquefied at $95{ }^{\circ} \mathrm{C}$ for $40 \mathrm{~min}$ by Liquozyme Supra $\alpha$-amylase $\left(0.0004 \mathrm{KNU} \mathrm{g}^{-1}\right.$ d.w. starch, $0.0003 \%$ d.w.). This process was terminated through inactivation of the $\alpha$-amylase by adjustment of $\mathrm{pH}$ to $4.0-4.2$. Then hydrolysate concentration was decreased to $30^{\circ} \mathrm{Bx}$.

The second step of amylolysis, i.e. saccharification was conducted for $48 \mathrm{~h}$ at $60{ }^{\circ} \mathrm{C}$ by using the glucoamylase (Dextrozyme, $0.0867 \mathrm{AGU} \mathrm{g}^{-1}$ d.w. hydrolysate, $0.34 \mathrm{~kg}$ enzyme $1000^{-1} \mathrm{~kg}$ d.w. hydrolysate).

\section{Determination of physicochemical properties of starch hydrolysates}

The following properties of starch hydrolysates were determined:

\section{- the rate of filtration}

An aliquot $\left(10 \mathrm{~cm}^{3}\right)$ of hydrolysate $\left(10^{\circ} \mathrm{Bx}\right)$ was filtered at $60{ }^{\circ} \mathrm{C}$ under the constant pressure of $0.88 \mathrm{~kg} \cdot\left(\mathrm{cm}^{3}\right)^{-1}$ (Millipore Corporation, Bredford, MA 01730, USA) through a $0.45 \mu \mathrm{m}$ membrane and the time of this process was measured [11].

- the compressibility of filtration cake

The solids remained after filtration of starch hydrolysates were lyophilized and analyzed for solid substance content. Before measurements of the compressibility, the lyophilizates were rehydrated at the lyophilizate d.w.: distilled water ratio of $4: 6$ for $12 \mathrm{~h}$ at $4{ }^{\circ} \mathrm{C}$. Then these samples were mixed to obtain a homogeneous paste.

The compressibility of filtration cakes was measured using a TA.XT Plus Texture Analyzer (Stable Micro Systems) equipped with an aluminum cylindrical probe $\mathrm{P} / 25$ (diameter of $25 \mathrm{~mm}$ ) from Stable Micro Systems and an aluminum cylindrical cell. Samples $(10 \pm 0.01 \mathrm{~g})$ of the rehydrated paste were placed in this cell and air bubbles were removed from them by repeated gentle knocking at the bottom of the cell that also enabled to level the surface of paste samples. The texture analyzer measured the maximum weight that was necessary to squeeze the $10 \mathrm{~g}$ sample with the thickness of $10 \mathrm{~mm}$.

\section{Statistical analysis}

All assays were carried out in triplicate and their results are presented as mean \pm standard deviation. The data were subjected to one-way analysis of variance (Anova), using computer program Statistica 7.1. Differences were regarded as statistically significant at $p<0.05$. 


\section{Results and discussion}

\section{Chemical composition of native starches and starches deprived of arabinoxylans}

The extent of starch hydrolysis depends, among others, on the size and order of crystalline regions of starch granules. The susceptibility of crystalline regions to degradation by amylolytic enzymes depends on the degree of their order. More ordered crystalline regions are less prone to hydrolysis [30]. Properties of wheat starch hydrolysates depend on the crystallinity of starch granules and their chemical composition. The physicochemical starch properties are affected by the substances associated with starch such as proteins, lipids and non-starch polysaccharides such as arabinoxylans. The results of proteins and lipids assays in the starches of facultative wheat varieties are collected in Table 1 . The protein contents in the native starches varied from 0.43 to $0.49 \%$ d.w. and were not statistically significantly affected by the sowing time and grain hardness. Quantification of proteins in the starches deprived of AX enabled to estimate the strength of interactions between $\mathrm{AX}$ and proteins associated with the surface of starch granules and its dependence on the sowing time and grain hardness. The results of this analysis showed that the amount of proteins removed along with AX depended on the sowing time, and more proteins were extracted from the spring sown crops than from the autumn sown counterparts. Furthermore, the amount of extracted proteins decreased with the increase in grain hardness. It suggests that the strength of interactions between the proteins and the surface of starch granules in grains of soft wheat varieties is lower than in case of hard varieties. Furthermore, it may be concluded that the strength of interactions between proteins and $\mathrm{AX}$ is stronger in the case of starch granules from the spring sown and less hard wheat grains. Of course, it is necessary to take into consideration the variable hardness of grains of the facultative wheat varieties, which are categorized as medium hard. It may be assumed that the strenght of the interaction between proteins and AX may be reflected in the molecular structure of AX. Besides the ratio of number of xylose residues substituted with arabinose to unsubstituted ones, the ratio of a number of xylose residues substituted with one arabinose residue to a number of xylose residues linked to two arabinose moieties is also important (Table 1). This ratio was higher in the case of preparations of WEAX that were isolated from harder grains of the facultative wheat varieties, obtained when they were sown in late autumn. This, in turn, suggests that xylose residues in AXs from autumn sown facultative wheat varieties are substituted with single arabinose residues in a greater extent than with double ones. Therefore, their interaction with molecules of proteins associated with the surface of starch granules are weaker. On the contrary, WEAX xylose residues from spring sown crops are to a greater extend double substituted than mono-substituted with arabinose residues. Therefore, their interactions with these proteins may be stronger, as mainly arabinose residues are the ones to bound to proteins.

The data presented in Table 1 demonstrate that extraction of AX from starch granules caused also the partial removal $(2.5-12.0 \%)$ of lipids and the percentage of lipids extracted with AX depended primarily on the wheat sowing time (statistically significant differences), and to the lesser extent on the grain hardness. More lipids were extracted from starch granules of the autumn sown wheat crops. In the case of the Cytra variety, which was characterized by the highest hardness of grains, the difference between amounts of lipids extracted from starch granules of the spring and autumn sown crops was only around $1 \%$. The percentage of lipids removed along with AX increased with the rise in the hardness of grains that suggests that the strength of interactions between the lipids and AX also increased with the hardness.

Table 1 The dependence of proteins and total lipids contents in native and AX-free starches and the ratio of xylose residues substituted with one or two arabinose residues in native starches on the sowing time of the facultative wheat varieties

\begin{tabular}{|c|c|c|c|c|c|c|c|}
\hline \multirow[t]{2}{*}{ Sowing time } & \multicolumn{2}{|l|}{ Native starch } & \multicolumn{2}{|c|}{ Starch without AX } & \multirow{2}{*}{$\begin{array}{l}\text { Removed } \\
\text { protein }(\%)\end{array}$} & \multirow{2}{*}{$\begin{array}{l}\text { Removed lipids } \\
(\%)\end{array}$} & \multirow[t]{2}{*}{$M / D$} \\
\hline & $\begin{array}{l}\text { Protein content } \\
\text { (\% d.w.) }\end{array}$ & $\begin{array}{l}\text { Lipid content } \\
\text { (\% d.w.) }\end{array}$ & $\begin{array}{l}\text { Protein content } \\
\text { (\% d.w.) }\end{array}$ & $\begin{array}{l}\text { Lipids content } \\
\text { (\% d.w.) }\end{array}$ & & & \\
\hline Koksa autumn & $0.43^{\mathrm{A} 1} \pm 0.02$ & $0.54^{\mathrm{a} 1} \pm 0.12$ & $0.20^{\mathrm{B} 1} \pm 0.01$ & $0.47^{\mathrm{a} 1} \pm 0.06$ & 53.5 & 12.6 & $5.54^{\mathrm{I}} \pm 0.46$ \\
\hline Koksa spring & $0.49^{\mathrm{A} 1} \pm 0.04$ & $0.58^{\mathrm{a} 1} \pm 0.03$ & $0.15^{\mathrm{B} 1} \pm 0.05$ & $0.54^{\mathrm{a} 1} \pm 0.02$ & 69.4 & 6.9 & $4.40^{\mathrm{II}} \pm 0.36$ \\
\hline Cytra autumn & $0.46^{\mathrm{A} 1} \pm 0.00$ & $0.53^{\mathrm{a} 1} \pm 0.04$ & $0.27^{\mathrm{B} 1} \pm 0.01$ & $0.48^{\mathrm{a} 1} \pm 0.03$ & 41.3 & 9.4 & $7.72^{\mathrm{I}} \pm 0.48$ \\
\hline Cytra spring & $0.45^{\mathrm{A} 1} \pm 0.01$ & $0.58^{\mathrm{a} 1} \pm 0.03$ & $0.16^{\mathrm{B} 2} \pm 0.03$ & $0.51^{\mathrm{b} 1} \pm 0.02$ & 65.4 & 12.0 & $6.62^{\mathrm{II}} \pm 0.39$ \\
\hline Nawra autumn & $0.45^{\mathrm{A} 1} \pm 0.00$ & $0.52^{\mathrm{a} 1} \pm 0.06$ & $0.21^{\mathrm{B} 1} \pm 0.01$ & $0.47^{\mathrm{a} 1} \pm 0.02$ & 53.3 & 9.6 & $3.82^{\mathrm{I}} \pm 0.25$ \\
\hline Nawra spring & $0.45^{\mathrm{A} 1} \pm 0.00$ & $0.47^{\mathrm{a} 1} \pm 0.10$ & $0.18^{\mathrm{B} 2} \pm 0.01$ & $0.45^{\mathrm{a} 1} \pm 0.02$ & 60.0 & 4.2 & $2.75^{\mathrm{II}} \pm 0.31$ \\
\hline
\end{tabular}

$M / D$ the ratio of xylose residues substituted with one or two arabinose residues

Means within each variable with different superscripts (capital letters relate to the difference in the amount of protein-lines, small letters relate to the difference in the amount of lipid-lines, arabic numerals relate to the difference in the amount of protein and lipids according to the sowing time for specific varieties of wheat—columns, roman numerals relate to the difference in the ratio of xylose residues substituted with one or two arabinose residues according to the sowing time for specific varieties of wheat-columns) are significantly different $(p \leq 0.05)$ 
Interestingly, the percentage of proteins (40\%-above $60 \%$ ) extracted along with $\mathrm{AX}$ from starch granules was higher compared with the percentage of extracted lipids $(2.5-12 \%)$. This difference suggests that the protein-AX interactions were stronger than the lipid-AX interactions. This finding is consistent with conclusions of other authors who also observed the strong interactions between starch granule associated wheat proteins and AX [13,31].

The effectiveness of the applied methods of AX extraction from starch granules was evaluated based on the results of qualitative and quantitative analysis of WEAX and WUAX fractions, contained in the native starches and starches remained after AX extraction (Fig. 1a, b). The differences in WEAX contents in the native starches (Fig. 1a) were statistically significant and much higher than the differences in WUAX and TOAX (Fig. 1a). The amounts of WEAX in starch granules from the facultative varieties that were sown in the spring were significantly lower than in the counterparts sown in autumn (Fig. 1a). The analysis of data presented in Fig. 1b suggests that the methods used to extract AX were efficient because nearly all WEAX and the high percentage of WUAX were removed from starch granules. The percentages of WUAX, which were not detached from starch granules depended on the sowing time, and

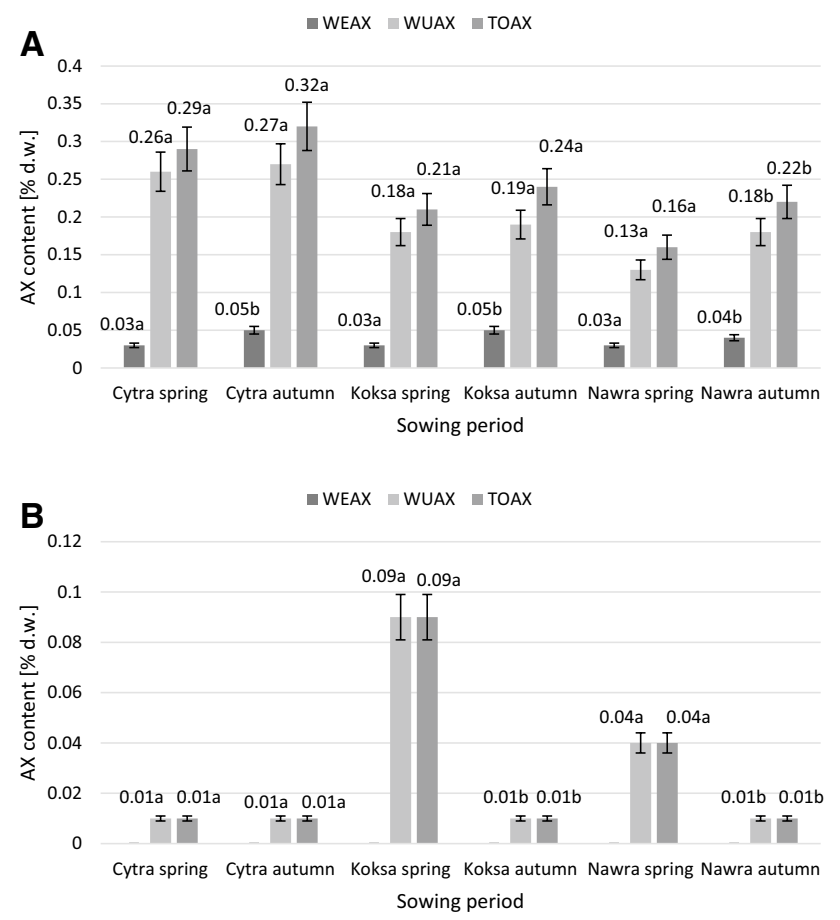

Fig. 1 The effect of sowing time of facultative wheat varieties on the effectiveness of AX extraction from starch granules (a native starch, b AX-free starch; WEAX water-extractable arabinoxylans, WUAX water-unextractable arabinoxylans, TOAX total arabinoxylans). Means within each variable with different superscripts (small letters relate to the sowing time for specific varieties of wheat) are significantly different $(p \leq 0.05)$ were $20,21,2,15,4$ and 14-fold lower compared to the native starches from spring and autumn sown crops of Cytra, Koksa and Nawra, respectively. Thus, more WUAX were removed from the starch granules when these varieties were sown in autumn.

The objective of further part of this work was to determine the impact of differences in chemical composition between the native and AX-free starches on the course of their gelatinization, formation and dissociation of AML complexes and susceptibility to degradation by $\alpha$-amylase as well as characteristics of glucose syrups derived from these starches such as color, filtration rate and compressibility of filtration cake.

\section{Thermodynamic properties of starch and dissociation/ re-association of AML complexes}

The knowledge about the parameters of starch gelatinization and the susceptibility of AML complexes to dissociation and re-association during starch gelatinization and liquefaction by $\alpha$-amylase, enables optimization of enzymatic hydrolysis conditions in terms of the highest quality of glucose syrups. The suitable analytical method, enabling optimization of starch thermal processing conditions and doses of amylolytic enzymes is DSC. The data describing the thermodynamics of starch gelatinization and association/dissociation/re-association of AML complexes formed in the native and $\mathrm{AX}$-free starches, either liquefied with the $\alpha$-amylase Termamyl 120L (Novozymes) or not, are presented in Table 2a, b. The dose of $\alpha$-amylase and the temperature of starch liquefaction were the same as in industry. The native starches were more prone to gelatinization than the AX-free counterparts (Table 2a) because of the higher values of gelatinization enthalpy $(\Delta H)$ and lower values of maximum temperature of gelatinization $\left(T_{\mathrm{p}}\right)$, and the onset and termination temperatures ( $T_{\mathrm{o}}$ and $T_{\mathrm{c}}$, respectively). The native and $\mathrm{AX}$-free starches derived from the crops sown in the spring were less susceptible to gelatinization (significantly higher values of $T_{\mathrm{p}}$ ) than the counterparts sown late autumn. The data presented in Table 2a demonstrate that the time of sowing of the facultative wheat varieties significantly affected the susceptibility of the starches to gelatinization. Sowing in the spring resulted in the significantly higher gelatinization temperatures $\left(T_{\mathrm{o}}, T_{\mathrm{p}}\right.$ and $\left.T_{\mathrm{c}}\right)$.

The susceptibility of starch to gelatinization is characterized by the value of $T_{\mathrm{p}}$. The higher is $T_{\mathrm{p}}$, the more energy is required to initiate gelatinization of starch granules [3234]. Thus, the starches isolated from the crops sown in the spring were less prone to gelatinization compared to the autumn sown counterparts. The differences in the enthalpy of starch conversion $(\Delta H)$ suggest that the starches contained different amounts of crystallites that are formed by amylopectin, which underwent melting transition [33, 34]. 


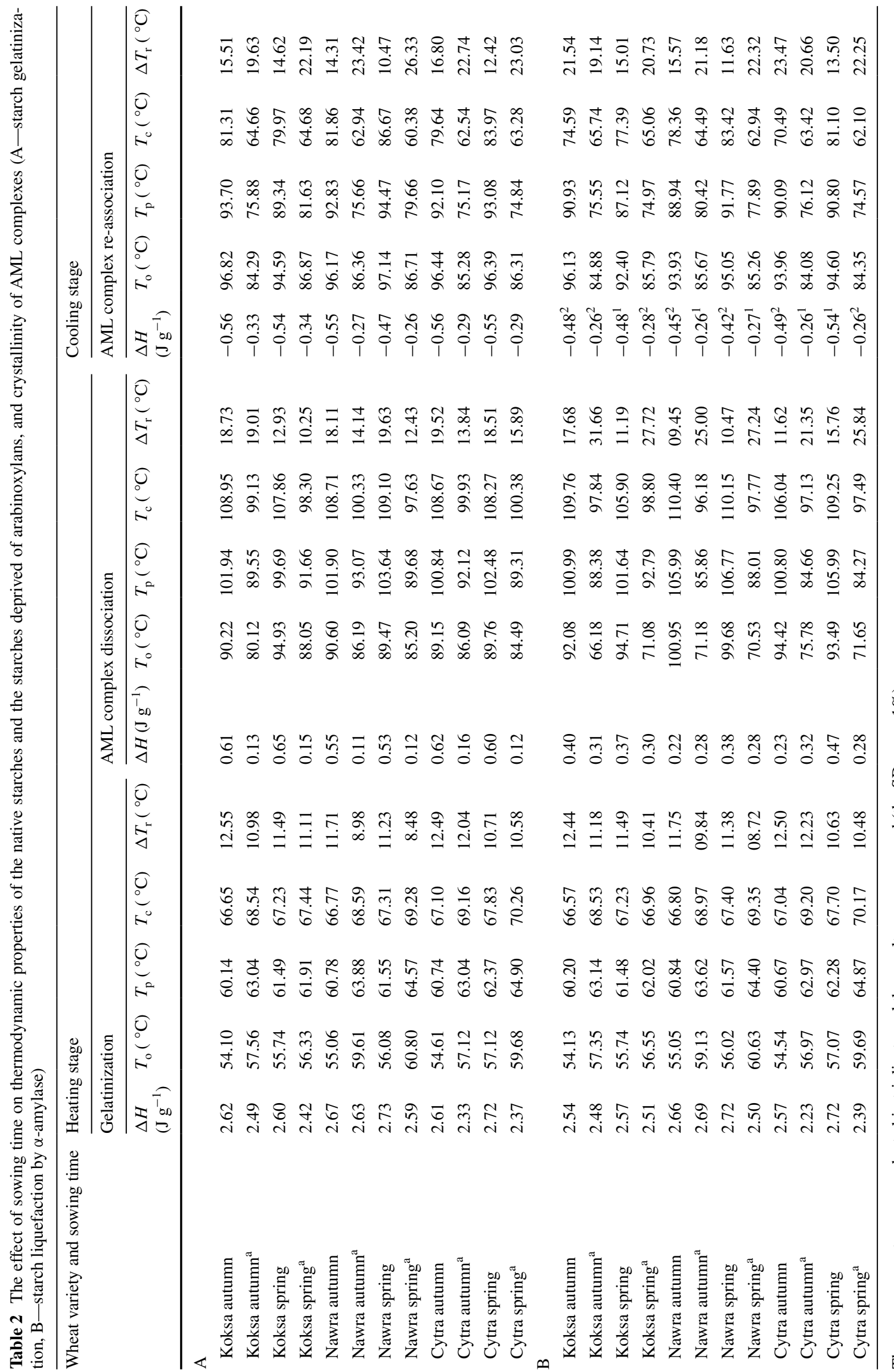

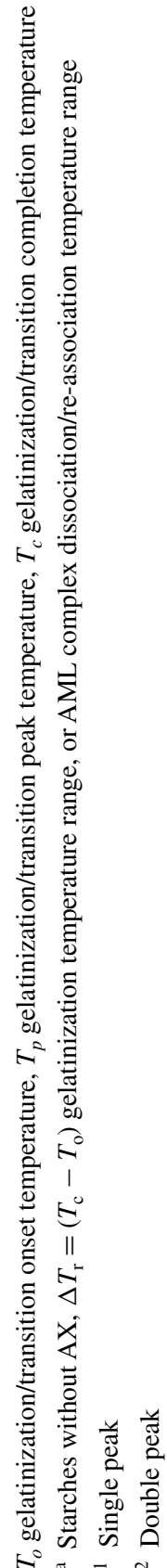


The values of $\Delta \mathrm{H}$ were significantly lower in the case of the starches isolated from the spring-sown crops than from the autumn-sown counterparts. The susceptibility of starch to gelatinization is also reflected by the range of gelatinization temperatures $\left(\Delta T_{\mathrm{r}}\right)$, which depends on the uniformity of crystalline regions of cereal starches [35-38]. More uniform crystalline structures of starch are characterized by the smaller difference between temperatures of gelatinization onset and completion $\left(\Delta T_{\mathrm{r}}=T_{\mathrm{o}}-T_{\mathrm{c}}\right)$. In the case of the starches isolated from the spring-sown crops of the tested facultative wheat varieties, the range of gelatinization temperatures $\left(\Delta T_{\mathrm{r}}\right)$ was significantly narrower in comparison to the autumn-sown counterparts, that could be caused by the greater uniformity of crystalline regions, which made the first starches less prone to gelatinization. The same tendency was observed in the case of the starches deprived of AX (Table 2a, gelatinization).

Interestingly, the removal of $\mathrm{AX}$ from the starches caused that the contents of AML complexes were around fourfold lower than in the native starches. It was concluded based on the comparison of the values of $\Delta \mathrm{H}$ of $\mathrm{AML}$ complexes dissociation in the native and AX-free starches (Table 2a). Furthermore, the AML complexes in the latter starches showed the higher tendency to re-association than in the native starches. This suggests that the removal of AX from the surface of starch granules creates suitable conditions for AML formation due to the easier access of lipids to amylose chains. Moreover, the polymorphs of AML complexes formed in the AX-free and native starches were different because the dissociation temperatures of the first complexes were by $8-10{ }^{\circ} \mathrm{C}$ lower (Table 2a, AML dissociation). This difference means that they were more amorphous and susceptible to enzymatic digestion [39-41]. In comparison to the starches from the autumn-sown crops, the native starches from the spring-sown facultative wheat varieties were characterized by the lower temperatures of AML complexes dissociation while in the case of the complexes formed in the AX-free starches this tendency was opposite.

Also, the character of curves in DSC thermograms reflects the thermodynamic conversions occurring in starch granules. The peaks attributed to starch gelatinization in the endothermic curves of the native and AX-free starches were similar (the curves were not presented). However, the peaks attributed to AML complexes dissociation were different. In the case of the AX-free starches, these peaks were wider and contained a characteristic dent, attributed to the excess of lipids, which were not bound in the AML complexes (Fig. 2a-native starches, Fig. 2bAX-free starches). These lipids were particularly visible in the starches from the spring-sown crops. This finding is consistent with the former observation of the authors who reported that starch granules from the spring-sown facultative wheat varieties contained more lipids on the surface than the late autumn-sown counterparts [24]. In the case of the AX-free starches, the peaks in exothermic curves attributed to AML complexes re-association during cooling of the gelatinized starches were wider and had a bimodal character, particularly in the case of the springsown (Fig. 2d), less prone to gelatinization starches. This suggests formation of two different AML polymorphs, which was reported in literature. For instance, Boltz and
Fig. 2 The effect of sowing time of facultative wheat varieties on the shape of endothermic curves of dissociation (a native starch, b starch without $\mathrm{AX})$ and exothermic curves of re-association (C-native starch, D-starch without AX) of AML complexes in starch liquefied by $\alpha$-amylase
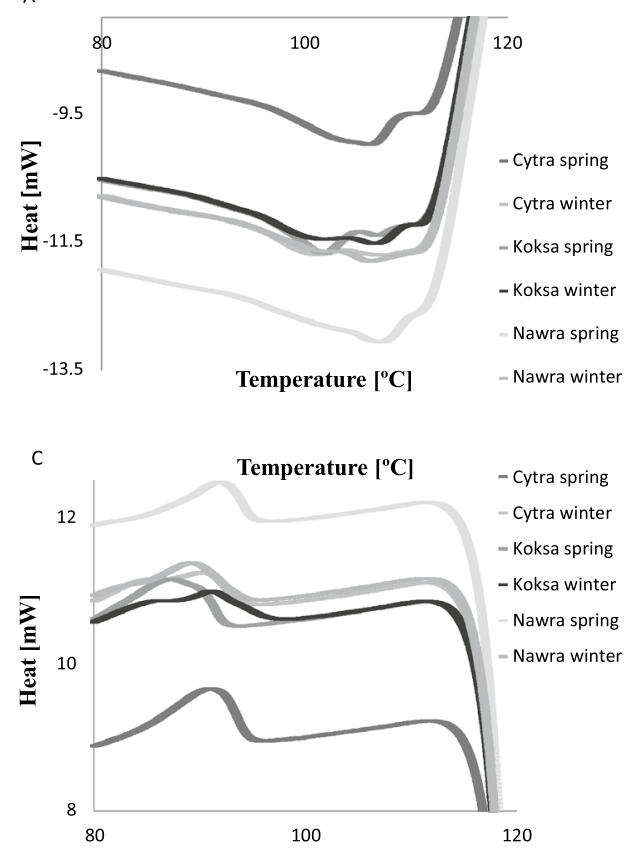

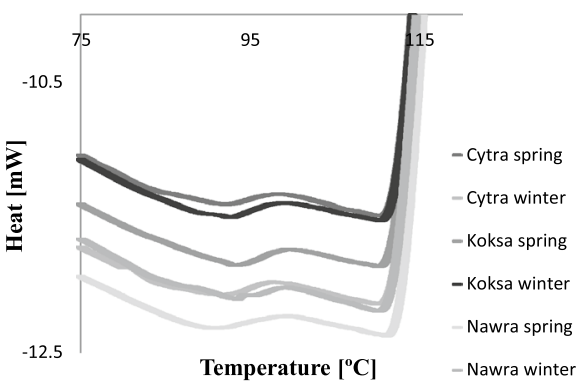

D

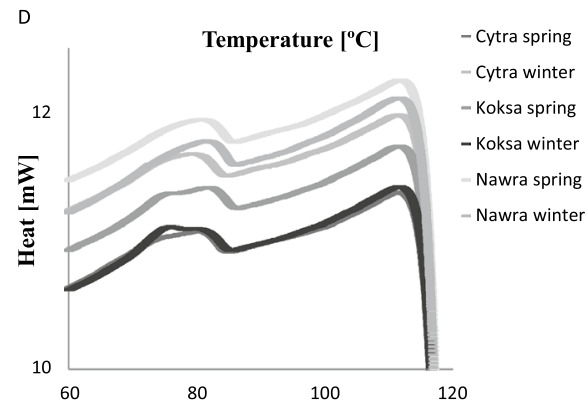


Thompson [42] who studied gelatinization of high-amylose starches, in which the amylose: lipids ratio was much higher than in the case of wheat starches, suggested that amylose chains did not undergo complete conformational reorganization during heating of starch suspensions, and only a part of amylose was able to form AML complexes. This phenomenon was not observed in the case of wheat starches and starches containing the similar amounts of amylose, because the studies reported in literature focused on different AML polymorphs of known structure that were formed in laboratory conditions $[40,41]$. The transitions of AML complexes during successive steps of heating and cooling have not been fully elucidated yet. It is thought that partial melting of the crystallites and dissociation of amylose and lipid take part when starch suspensions are heated while cooling of gelatinized starch brings about re-association of crystallites [43]. However, further studies are necessary to explain these phenomena in more detail. The results of DSC analysis of starch hydrolysates obtained from the native and AX-free starches using $\alpha$-amylase are presented in Table $2 b$. The data describe the course of starch gelatinization as well as dissociation and re-association of AML complexes formed in the enzymatically digested starch. Comparison of these data proves that the AX-free starches were less prone to degradation by $\alpha$-amylase than the native ones because the peak gelatinization temperatures $\left(T_{\mathrm{p}}\right)$ were by $2-3{ }^{\circ} \mathrm{C}$ higher, irrespective of the sowing time (Table $2 \mathrm{~b}$, gelatinization). The values of AML dissociation enthalpy $(\Delta H)$ were significantly lower in the case of the AX-free starches. The AML complexes were more prone to degradation by $\alpha$-amylase in the case of the native and AX-free starches from the autumn-sown crops. After liquefaction with $\alpha$-amylase, the AML complexes formed in AX-free starches were less crystalline (more amorphous) as proved by the lower Tp temperatures (by $10-20^{\circ} \mathrm{C}$ ) of their dissociation (Table $2 \mathrm{~b}$, dissociation). Thus, these complexes were more susceptible to enzymatic hydrolysis than the complexes formed in the liquefied native starches. The AML complexes formed in AX-free starches, isolated from the autumn-sown crops, were characterized by the lower $T_{\mathrm{p}}$ temperatures than their spring-sown counterparts. This suggests that they occurred in the easily degradable by $\alpha$-amylase, amorphous form (Table $2 \mathrm{~b}$, dissociation). The values of enthalpy $(\Delta H)$ of re-association of AML complexes formed in the AX-free starches, liquefied with $\alpha$-amylase, were significantly lower compared to the native starches (Table $2 b$, re-association) that suggests their lower tendency to re-association.

The values of $\Delta T_{\mathrm{r}}$, which characterize the uniformity of crystalline regions, were around 2-2.5-fold greater in the case of the dissociation of AML complexes formed in $\mathrm{AX}$-free, liquefied starches, compared to the native starches (Table $2 \mathrm{~b}$, dissociation). The larger is $\Delta T_{\mathrm{r}}$ value, the less crystalline and more susceptible to enzymatic degradation is AML complex [24]. Therefore, filtration of the hydrolysates obtained from AX-free starches was faster (Fig. 2a). Also the values of $\Delta T_{\mathrm{r}}$ of AML complexes re-association after $\mathrm{AX}$-free starch liquefaction with $\Delta$-amylase were lower compared to the native starches (Table $2 b$, re-association).

The character of peaks in exothermic curves depicting the re-association of AML complexes provides evidence that only one form appeared in AX-free starches (the single peak in each of the curves, Table $2 b$, re-association) while two polymorphs were formed in native starches (two peaks in the curves, Table $2 \mathrm{~b}$, re-association). Also, this may explain the differences in the susceptibility of these starches to enzymatic hydrolysis and physicochemical properties of glucose syrups, including filtration rate (Fig. 3a) and compressibility of filtration cakes (Fig. 3b).

\section{Filtration performance of glucose syrups}

Filtration performance of glucose syrups obtained from the native and AX-free starches was different (Fig. 3a). Filtration of the hydrolysates obtained from the AX-free starches was much faster compared to the hydrolysates of native
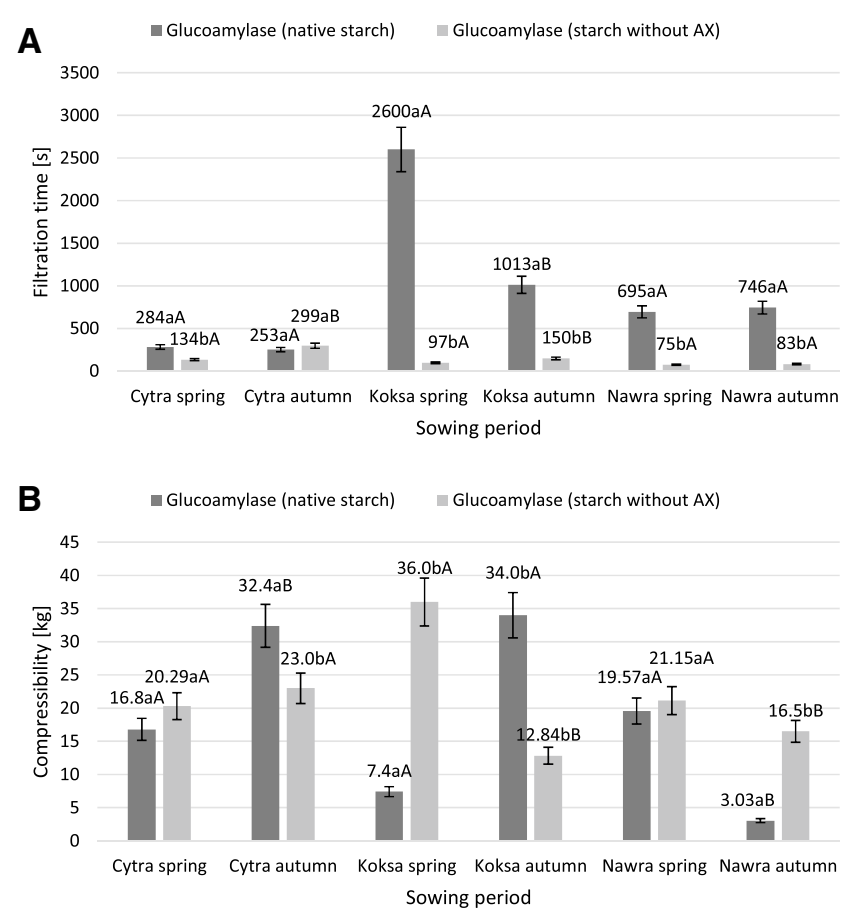

Fig. 3 Filtration rates (a) and compressibility of filtration cakes (b) of hydrolysates of native and AX-free starches. Means within each variable with different superscripts (small letters relate to the same variety of wheat for specific sowing time, capital letters relate to the sowing time for specific varieties of wheat) are significantly different $(p \leq 0.05)$ 
starches, irrespective of the time of sowing of the facultative wheat varieties, with an exception of the autumn-sown Cytra variety. Filtration of the hydrolysate of the AXfree starch derived from its grains was longer compared to the hydrolysate of the native Cytra starch (autumnsown) which was consistent with the lower value of $\Delta T_{\mathrm{r}}$ $\left(20.66{ }^{\circ} \mathrm{C}\right)$ of AML complex re-association (Table $2 \mathrm{~b}$, reassociation) in the liquefied by $\alpha$-amylase $\mathrm{AX}$-free starch compared to that of the native starch $\left(23.47{ }^{\circ} \mathrm{C}\right)$. Thus, the first AML complexes had more ordered crystalline structure and were more resistant to saccharification by glucoamylase. In general, filtration of glucose syrups from the AX-free starches isolated from autumn-sown crops was longer compared to the spring-sown counterparts while in the case of the hydrolysates of the native starches this tendency was opposite (Fig. 3a). It may be ascribed to the properties of AML complexes formed in the hydrolysates of AX-free starches (around twofold higher values of $\Delta T_{\mathrm{r}}$ compared to the complexes formed in the hydrolysates of native starches, Table $2 b$, dissociation).

\section{The compressibility of filtration cakes from enzymatic starch hydrolysates}

The compressibility of solid residues remained after filtration of the hydrolysates of the native and AX-free starches was different and correlated with transitions of AML complexes. The higher is the force necessary to squeeze the given amount of precipitate, the better is filtration performance of the given enzymatic hydrolysate. The results of measurements show that the removal of AX from the surface of starch granules significantly increased the compressibility of filtration cakes remaining after filtration of glucose syrups (Fig. 3b), which was consistent with the shorter filtration time (Fig. 3a). The less crystalline structure of AML complexes formed in the hydrolysates of AXfree starches (greater values of $\Delta T_{\mathrm{r}}$, Table $2 \mathrm{~b}$, dissociation) makes these complexes more susceptible to enzymatic degradation. Simultaneously, the texture of filtration cake is less gel-like and pasty, and more dry and tight. The changes in the texture and form of the solids, which remained after enzymatic starch hydrolysis, caused that filtration of the hydrolysates from the AX-free starches was faster.

The results of DSC analysis demonstrate that AX associated with the surface of starch granules affect the susceptibility of starch to gelatinization and liquefaction by $\alpha$-amylase. This technique enables monitoring of transitions occurring in starch granules and their dependence on process parameters. However, the authors could not discuss the presented results with findings of other authors because of the lack of similar reports. As far as we know, only the effect of the presence of $\mathrm{AX}$ in the flour, whole cereal grains and various parts of the husk was described in the literature.

\section{Conclusion}

Reassuming, the results of DSC analysis showed that the removal of AX from wheat starch granules significantly changed the thermodynamics of starch gelatinization and association/dissociation/re-association of AML complexes, and improved the quality of enzymatic hydrolysates. The AX-free starches were more prone to liquefaction by $\alpha$-amylase and the AML complexes formed were less crystalline than the complexes formed in the native starches, which were more resistant to degradation by $\alpha$-amylase and glucoamylase (this conclusion was based on the values of $\left.\Delta T_{\mathrm{r}}\right)$. This, in turn, caused that filtration of hydrolysates from the AX-free starches was faster and the compressibility of filtration cakes was greater. Filtration performance of the glucose syrups obtained from the native starches isolated from autumn-sown facultative wheat varieties was better compared to the syrups from the spring-sown counterparts. The removal of AX from the surface of starch granules reduced this difference. The results of this study may help to solve the problems related to filtration of glucose syrups in industry. These problems, such as low filtration rates, dark color, and haze, are caused mainly by the arabinoxylans associated with the surface of starch granules.

Acknowledgements This study was financially supported by the Ministry of Science and High Education in Poland Project No. N N312 4645 40. The authors would like to thank Doctor Zygmunt Nita from the Institute of Plant Breeding in Strzelce-Group IHAR (Poland) for the kindly donated grains of facultative wheat varieties.

\section{Compliance with ethical standards}

Conflict of interest The authors declare that they have no conflict of interest.

Compliance with ethics requirements This manuscript does not describe any studies with human or animal subjects.

Open Access This article is distributed under the terms of the Creative Commons Attribution 4.0 International License (http://creativecommons.org/licenses/by/4.0/), which permits unrestricted use, distribution, and reproduction in any medium, provided you give appropriate credit to the original author(s) and the source, provide a link to the Creative Commons license, and indicate if changes were made.

\section{References}

1. Morrison WR (1995) Starch lipids and how they relate to starch granule structure and functionality. Cereal Food World 40:437-446

2. Baldwin PM (2001) Starch granule-associated proteins and polypeptides: a review. Starch/Stärke 53:475-503

3. Bocharnikova I, Wassermann LA, Krivadin AV, Fornal J, Błaszczak W, Chernykh VY, Yuryev VP (2003) Structure and 
thermodynamic melting parameters of wheat starches with different amylose content. J Therm Anal Calorim 74:681-695

4. Kaukovirta-Norja A, Reinikainen P, Ollku J, Laakso S (1997) Starch lipids of barley and malt. Cereal Chem 74:733-738

5. Kitahara K, Tanaka T, Suganuma T, Nagahama T (1997) Release of bund lipids in cereal starches upon hydrolysis by glucoamylase. Cereal Chem 74:1-6

6. Błaszczak W, Valverde S, Fornal J, Amarowicz R, Lewandowicz G, Borkowski K (2003) Changes in the microstructure of wheat, corn and potato starch granules during extraction of non-starch compounds with sodium dodecyl sulfate and mercaptoethanol. Carbohydr Polym 53:63-73

7. Debet MR, Gidley MJ (2006) Three classes of starch granule swelling: influence of surface proteins and lipids. Carbohydr Polym 64:452-465

8. Alcázar-Alay SC, Meireles MAA (2015) Physicochemical properties, modifications and applications of starches from different botanical sources. Food Sci Technol (Campinas) 35:215-236

9. Matser AM, Steeneken PAM (1998) Origins of the poor filtration characteristics of wheat starch hydrolysates. Cereal Chem 75:289-293

10. Bowler B, Towersey PJ, Galliard T (1985) Some effects of the minor components of wheat starch on glucose syrup production. Starch/Stärke 37:351-356

11. Matser AM, Steeneken PAM (1998) Filtration characteristics of maize and wheat starch hydrolysates. Cereal Chem 75:241-246

12. Rosicka-Kaczmarek J, Komisarczyk A, Nebesny E, Makowski B (2016) The influence of arabinoxylans on the quality of grain industry products. Eur Food Res Technol 242:295-303

13. Rosicka-Kaczmarek J, Kwaśniewska-Karolak I, Nebesny E, Miśkiewicz K (2013) Influence of variety and year cultivation on the chemical composition of starch and properties of glucose hydrolysates. J Cereal Sci 57:98-106

14. Tester RF, Morrison WR, Ellis RP, Piggott JR, Wheeler TR, Morison JIL, Hadley P, Ledward D (1995) Effects of elevated growth temperature and carbon dioxide levels on some physicochemical properties of wheat starch. J Cereal Sci 22:65-71

15. Tester RF (1997) Influence of growth conditions on barley starch properties. Int J Biol Macromol 21:37-45

16. Tester RF, Karkalas J (2001) The effect of environmental conditions on the structural features and physicochemical properties of starches. Starch/Stärke 53:513-519

17. Myllärinen P, Schulman AH, Salovaara H, Poutanen K (1998) The effects of growth temperature on gelatinization properties of barley starch. Acta Agr Scand B-S P 48:85-90

18. Myszkiewicz D (2012) Przewódki. Instytut Hodowli i Aklimatyzacji Roślin-Państwowy Instytut Badawczy. Hodowla Roślin Strzelce in Poland (in Polish)

19. Neugschwandtner RW, Böhm K, Hall RM, Kaul HP (2015) Development, growth, and nitrogen use of autumn- and springsown facultative wheat. Acta Agr Scand B-S P 65:6-13

20. Cacak-Pietrzak G (2008) Wykorzystanie pszenicy w różnych gałęziach przemysłu spożywczego- wymagania technologiczne. Przegląd Zbożowo-Młynarski 11:11-13 (in Polish)

21. Ozturk A, Caglar O, Bulut S (2006) Growth and yield response facultative wheat to winter sowing, freezing sowing and spring sowing at different seeding rates. J Agron Crop Sci 192:10-16

22. Okic A (1995) Produktivnost fakultativne sorte psenice Zemunka $1 \mathrm{u}$ jesenjoj i prolecnoj setvi. Selekcja i Semenarstwo 2:195-199

23. Williams PC (2000) Applications of the Perten SKCS 4100 in flour-milling. Association of operative millers bulletin. March, pp 7421-7424

24. Rosicka-Kaczmarek J, Makowski B, Nebesny E, Tkaczyk M, Komisarczyk A, Nita Z (2016) Composition and thermodynamic properties of starches from facultative wheat varieties. Food Hydrocolloids 54:66-76
25. Saylaslan A (2004) Wet-miling of wheat flour: industrial processes and small-scale test methods. LWT Food Sci Technol 37:499-515

26. AACC International Approved Methods of the American Association of Cereal Chemists, AACC method 46-12 Kjeldahl nitrogen analysis 1983

27. Gebruers K, Courtin ChM, Delcour JA, Shewry PR, Ward JL (2009) Analysis of bioactive grain cereals quantification of arabinoxylans and their degree of branching using gas chromatography. AACC Int Adv Grain Sci Worldw 14:177-183

28. Toole GA, Gall GL, Colquhoun IJ, Johnson P, Bedö Z, Saulnier L, Shewry PL, Clare Mills EN (2011) Spectroscopic analysis of diversity of arabinoxylan structures in endosperm cell walls of wheat cultivars (Triticum aestivum) in the HEALTHGRAIN diversity collection. J Agric Food Chem 59:7075-7082

29. Nebesny E, Rosicka-Kaczmarek J, Tkaczyk M (2005) Influence of selected parameters of starch gelatinization and hydrolysis on stability of amylose-lipid complexes. Starch/Stärke 57:325-331

30. Buleon A, Colonna P, Planchot V, Ball S (1998) Starch granules: structure and biosynthesis. Int J Biol Macromol 23:85-112

31. Konieczny-Janda G, Richter G (1991) Progress in the enzymatic saccharification of wheat starch. Starch/Stärk 43:308-315

32. Coral DF, Pineda-Gomez P, Rosales-Rivera A, Rodriguez-Garcia ME (2009) Determination of the gelatinization temperature of starch presents in maize flours. J Phys Conf Ser 167:1-5

33. Ubwa ST, Abah J, Asemave K, Shambe T (2012) Studies on the gelatinization temperature of some cereal starches. Int J Chem 4:22-28

34. Chen P, Liu X, Zhang X, Sangwan P, Yu L (2015) Phase transition of waxy and normal wheat starch granules during gelatinization. Int J Polym Sci 1:1-7

35. Nwokocha LM, Nwokocha KE, Williams PA (2012) Physicochemical properties of starches isolated from Antiaris Africana seeds in comparison with maize starch. Starch/Stärke 64:246-254

36. Nwokocha LM, Williams PA (2009) New starches: physicochemical properties of sweetsop (Annona squamosal) and soursop (Annona muricata) starches. Carbohydr Polym 78:462-468

37. Kaur A, Singh N, Ezekiel R, Guarya HS (2009) Properties of starches separated from potatoes stored under different conditions. Food Chem 114:1396-1404

38. Kiseleva VI, Tester RF, Wasserman LA, Krivadin AV, Popov AA, Yuryev VP (2003) Influence of growth temperature on the structure and thermodynamic parameters of barley starches. Carbohydr Polym 51:407-415

39. Biliaderis CG, Seneviratne HD (1990) On the supermolecular structure and metastability for glycerol monostearate-amylose complex. Carbohydr Polym 71:887-891

40. Tufvesson F, Wahlgren M, Eliasson AC (2003) Formation of amylose-lipid complexes and effects of temperature treatment. Part 1, Monoglycerides. Starch/Stärke 55:61-71

41. Tufvesson F, Wahlgren M (2003) Eliasson AC formation of amylose-lipid complexes and effects of temperature treatment. Part 2. fatty acids. Starch/Stärke 55:138-149

42. Boltz KW, Thompson DB (1999) Initial heating temperature and native lipid affects ordering of amylose during cooling of high amylose starches. Cereal Chem 76:204-212

43. Eliasson AC (1994) Interactions between starch and lipids studied by DSC. Thermochim Acta 264:343-356 